\title{
PENCAPAIAN STANDAR KOMPETENSI SISWA SMK NEGERI PROGRAM KEAHLIAN TATA BUSANA DI KOTA YOGYAKARTA DALAM PEMBELAJARAN DENGAN KBK
}

\author{
Oleb: \\ Widibastuti
}

\begin{abstract}
Abstrak
Artikel ini ditulis berdasarkan hasil penelitian evaluasi keefektifan pembelajaran pada penerapan KBK di Program Keahlian Tata Busana Kota Yogyakarta.

Penelitian ini merupakan penelitian evaluasi dengan pendekatan kuantitatif. Populasi penelitian meliputi 671 siswa Program Keahlian Tata Busana SMK Negeri di Kota Yogyakarta yang telah melaksanakan KBK. Sampel penelitian sebanyak 137 siswa yang ditentukan dengan teknik proportional stratified random sampling menggunakan rumus Krejcie \& Morgan. Data penelitian diperoleh dari dokumen nilai prestasi akademik siswa, yang meliputi nilai normatif, adaptif, dan produktif. Teknik analisis menggunakan statistik deskriptif dan inferensial dengan bantuan komputer paket program SPSS 10 for windows.

Hasil penelitian menunjukkan bahwa: pembelajaran pembentukan kompetensi normatif cukup efektif, dan pembentukan kompetensi adaptif dan produktif kurang efektif.

Kata kunci: pencapaian standar kompetensi siswa.
\end{abstract}

\section{Pendahuluan}

Salah satu permasalahan utama di bidang pendidikan khususnya Sekolah Menengah Kejuruan (SMK) adalah rendahnya mutu atau kualitas lulusan dilihat dari belum sesuainya kompetensi lulusan dengan harapan pihak industri atau lapangan kerja. Kualitas lulusan SMK ditentukan oleh kualitas proses pembelajaran dengan karakteristik porsi pembelajaran praktek yang cukup besar. 
Pencapaian Standar Kompetensi Sisva SMK Negeri Program Keablian Tata Busana di Kota Yogyakarta dalam Pembelajaran dengan KBK

Berkaitan dengan hal di atas, maka pemerintah berupaya meningkatkan kualitas pendidikan melalui kebijakan penerapan dan pelaksanaan Kurikulum Berbasis Kompetensi (KBK) di sekolah mulai tahun ajaran 2004/2005, termasuk di SMK Program Keahlian Tata Busana yang ada di Kota Yogyakarta. Menurut Djemari Mardapi (2004: 2), penerapan KBK disemua jenjang pendidikan menuntut kompetensi lulusan yang jelas dan memberi tantangan bagi setiap lembaga pendidikan agar setiap siswanya dapat mencapai kriteria atau standar kompetensi yang telah ditetapkan. Tantangan ini akan membangkitkan motivasi sekolah untuk dapat mencapai kriteria atau standar kompetensi tersebut dengan memotivasi guru untuk lebih meningkatkan lagi kualitas pembelajarannya, dan memotivasi siswa untuk belajar lebih baik lagi. Standar kompetensi lulusan yang jelas tersebut akan dapat menentukan daya saing lulusan setiap lembaga pendidikan.

Kompetensi menurut Harris (1995: 20) adalah: "The possession and development of sufficient skills, appropriate attitudes and experience for succesfful performance in life roles". Dijelaskan lebih lanjut bahwa kompetensi kejuruan (vocational competence) adalah "an underlying characteristic of a person which results in effective and/or superior performance in a job". Menurut Spencer and Spencer (1993: 9) kompetensi adalah:

An underlying characteristic of an individual that is causally related to criterionreferenced effective and or superior performance in a job or situation. Underlying characteristic means the competengy is a fairly deep and enduring part of a person's personality and can predict bebavior in a vide variety of situations and job tasks. Causally related means that a competengy causes or predicts behavior and performance. Criterion-referenced means that the competency actually predicts who does something well or poorly, as measured on a specific criterion or standard.

Association Education (2000) mendefinisikan bahwa: "competency refers to an individual's demonstrated knowledge, skills, and abilities performed to a specific standard". Pengertian standar kompetensi menurut Gonezi (1992: 226) adalah " $A$ standard (or competency standard) is a minimum acceptable level of performance in an area of competence". Standar kompetensi adalah tingkat kinerja minimal yang dituntut oleh bidang kompetensi tertentu. 
Hasil kegiatan pembelajaran pada Program Keahlian Tata Busana dapat diketahui melalui unjuk kerja siswa pada seperangkat kompetensi yang telah ditetapkan, dari aspek kognitif, afektif, dan psikomotor. Pada awal penerapan KBK, sebagai kurikulum baru, nampak belum adanya kesiapan yang memadai dari pihak pelaksana di lapangan, khususnya guru dan siswa. Keluhan yang sering muncul adalah belum semua guru memahami konsep KBK dan bagaimana pengembangan silabus, penilaian berkelanjutan, penggunaan media dan metode mengajar yang bervariasi. Di samping itu masih ada guru yang belum menyampaikan kompetensi yang harus dimiliki siswa sebelum memulai KBM, dan belum memanfaatkan sumber belajar lain seperti perpustakaan dan Internet, sehingga masih ada guru yang menganggap bahwa KBK masih merupakan barang baru yang memusingkan dan memberatkan (Zamroni, 2004: 2).

Dengan demikian, perlu dievaluasi apakah pembelajaran dengan KBK di SMK Negeri Program Keahlian Tata Busana di Kota Yogyakarta telah efektif ditinjau dari pencapaian standar kompetensi siswa. Hasil evaluasi diharapkan dapat digunakan untuk perbaikan dan penyempurnaan selanjutnya.

\section{Metode Penelitian}

Penelitian ini dilaksanakan di Program Keahlian Tata Busana SMK Negeri di Kota Yogyakarta yang meliputi SMK N 4 Yogyakarta dan SMK N 6 Yogyakarta, yang pada saat dilakukan penelitian ini sedang melaksanakan KBK dengan memberlakukan Kurikulum SMK Edisi 2004, dan penelitian ini dilaksanakan selama 4 bulan yaitu pada semester genap tahun ajaran 2005/2006. Penelitian ini merupakan penelitian evaluasi dengan pendekatan kuantitatif. Populasi penelitian meliputi 671 siswa Program Keahlian Tata Busana SMK Negeri di Kota Yogyakarta, dan sampel penelitiannya sebanyak 137 siswa yang ditentukan dengan teknik proportional stratified random sampling menggunakan rumus Krejcie \& Morgan. Data penelitian diperoleh dari dokumen nilai prestasi alkademik siswa, yang meliputi nilai normatif, adaptif, dan produktif. Teknik analisis data yang 
Pencapaian Standar Kompetensi Siswa SMK Negeri Program Keablian Tata Busana di Kota Yogyakarta dalam Pembelajaran dengan KBK

digunakan adalah teknik analisis data statistik deskriptif dan inferensial dengan bantuan komputer paket program SPSS 10 for windows.

\section{Hasil dan Pembahasan}

Penilaian prestasi akademik siswa baik dari nilai normatif, adaptif, maupun produktif, dan pengkategorian pencapaian standar kompetensi siswa Program Keahlian Tata Busana mengacu pada kriteria yang ditetapkan oleh Depdiknas seperti pada Tabel 1. Distribusi frekuensi pengkategorian pencapaian standar kompetensi siswa baik dilihat dari nilai normatif, adaptif, maupun produktif siswa SMK Negeri Program Keahlian Tata Busana di Kota Yogyakarta yang meliputi SMKN 4 Yogyakarta dan SMKN 6 Yogyakarta dapat dilihat pada Tabel 2.

\section{Tabel 1}

Pengkategorian Prestasi Akademik dan Pencapaian Standar Kompetensi Siswa

\begin{tabular}{|c|c|}
\hline Kategori & Interval Nilai \\
\hline Sangat baik & $8,5-10$ \\
\hline Baik & $7,0-8,4$ \\
\hline Cukup & $5,5-6,9$ \\
\hline Kategori & Interval Nilai \\
\hline Kurang & $4,0-5,4$ \\
\hline Sangat kurang & $0,0-3,9$ \\
\hline
\end{tabular}

Tabel 1, Tabel 2, dan Tabel 3, menunjukkan bahwa rerata/mean nilai normatif sebesar 7,266 (> 7,0), dicapai oleh 130 siswa (94,9\%) dari 137 siswa $(>70 \%)$, sehingga dapat dikatakan bahwa siswa SMK Negeri Program Keahlian Tata Busana di Kota Yogyakarta telah berhasil mencapai standar minimal kompetensi nilai normatif yang telah ditetapkan yaitu $>70 \%$ siswa telah dapat mencapai nilai normatif dalam kategori baik $(>7,0)$. 
Tabel 2

Distribusi Frekuensi dan Pengkategorian Pencapaian Standar Kompetensi Siswa SMK Negeri Program Keahlian Tata Busana di Kota Yogyakarta

\begin{tabular}{|l|c|c|c|c|c|c|}
\hline \multirow{2}{*}{ Nilai } & Valid & Kategori & $\begin{array}{c}\text { Frequ- } \\
\text { ency }\end{array}$ & Percent & $\begin{array}{c}\text { Valid } \\
\text { Precent }\end{array}$ & $\begin{array}{c}\text { Cummula- } \\
\text { tive Precent }\end{array}$ \\
\hline \multirow{2}{*}{$\begin{array}{l}\text { NORMA- } \\
\text { TIF }\end{array}$} & Valid & Cukup & 7 & 5.1 & 5.1 & 5.1 \\
\hline & & Baik $>7.0$ & $\mathbf{1 3 0}$ & $\mathbf{9 4 . 9}$ & $\mathbf{9 4 . 9}$ & 100.0 \\
\hline \multirow{2}{*}{ ADAPTIF } & Valid & Cukup & 46 & 33.6 & 33.6 & 33.6 \\
\cline { 3 - 6 } & & Baik $>7.0$ & $\mathbf{9 1}$ & $\mathbf{6 6 . 4}$ & $\mathbf{6 6 . 4}$ & 100.0 \\
\hline \multirow{2}{*}{$\begin{array}{l}\text { PRO- } \\
\text { DUKTIF }\end{array}$} & \multirow{2}{*}{ Valid } & Cukup & 10 & 7.3 & 7.3 & 7.3 \\
\cline { 3 - 6 } & & $7.0<$ Baik $<7.5$ & 47 & 34.3 & 34.3 & 41.6 \\
\cline { 3 - 6 } & & Baik $\geq 7.5$ & $\mathbf{8 0}$ & $\mathbf{5 8 . 4}$ & $\mathbf{5 8 . 4}$ & 100.0 \\
\hline
\end{tabular}

\section{Tabel 3}

Hasil Analisis Data Statistik Deskriptif Nilai Normatif, Adaptif, dan Produktif Siswa SMK Negeri Program Keahlian Tata Busana di Kota Yogyakarta

Statistics

\begin{tabular}{|c|c|c|c|c|}
\hline & & NORMATIF & ADAPTIF & PRODUKTI \\
\hline \multirow[t]{2}{*}{$\mathbf{N}$} & Valid & 137 & 137 & 137 \\
\hline & Missing & 0 & $\mathbf{0}$ & 0 \\
\hline \multicolumn{2}{|l|}{ Mean } & 7.266 & 7.055 & 7.488 \\
\hline \multicolumn{2}{|c|}{ Std. Error of Mean } & $1.926 E-02$ & 2.297E-02 & 3.108E-02 \\
\hline \multicolumn{2}{|l|}{ Median } & 7.245 & 7.094 & 7.532 \\
\hline \multicolumn{2}{|l|}{ Mode } & $7.0^{\mathrm{a}}$ & 6.8 & $7.6^{\circ}$ \\
\hline \multicolumn{2}{|c|}{ Std. Deviation } & .225 & .269 & .364 \\
\hline \multicolumn{2}{|l|}{ Variance } & 5.079E-02 & $7.228 E-02$ & .132 \\
\hline \multicolumn{2}{|l|}{ Skewness } & .312 & .369 & -.933 \\
\hline \multicolumn{2}{|c|}{ Std. Error of Skewness } & .207 & .207 & .207 \\
\hline \multicolumn{2}{|l|}{ Kurtosis } & 1.319 & 1.646 & 1.244 \\
\hline \multicolumn{2}{|c|}{ Std. Error of Kurtosis } & .411 & .411 & .411 \\
\hline \multicolumn{2}{|l|}{ Range } & 1.4 & 1.8 & 2.0 \\
\hline \multicolumn{2}{|l|}{ Minimum } & 6.6 & 6.4 & 6.3 \\
\hline \multicolumn{2}{|l|}{ Maximum } & 8.1 & 8.2 & 8.2 \\
\hline \multicolumn{2}{|l|}{ Sum } & 995.4 & 966.5 & 1025.9 \\
\hline \multirow[t]{5}{*}{ Percentiles } & 10 & 7.014 & 6.690 & 7.000 \\
\hline & 25 & 7.131 & 6.865 & 7.310 \\
\hline & 50 & 7.245 & 7.094 & 7.532 \\
\hline & 75 & 7.383 & 7.220 & 7.726 \\
\hline & 90 & 7.571 & 7.373 & 7.891 \\
\hline
\end{tabular}

a. Multiple modes exist. The smallest value is shown 
Berdasarkan hal tersebut, maka tingkat keefektifan pembelajaran dengan KBK ditinjau dari pencapaian standar nilai normatif siswa SMK Negeri Program Keahlian Tata Busana di Kota Yogyakarta sudah dapat dimasukkan dalam kategori tinggi. Namun demikian, karena dilihat dari sebaran nilai normatif siswa masih kurang bagus (Nilai Mean $=7,266>$ Nilai Median= 7,245 > Nilai Modus= 7,0), maka pencapaian nilai normatif siswa SMK Negeri Program Keahlian Tata Busana di Kota Yogyakarta ini masih perlu ditingkatkan lagi agar dapat mencapai hasil yang lebih memuaskan.

Hasil ringkasan statistik deskriptif Uji-t Nilai Normatif menunjukkan bahwa SMKN 4 Yogyakarta mempunyai skor rata-rata 7,244; sedangkan SMKN 6 Yogyakarta mempunyai skor rata-rata 7,288; dan hasil Uji-t nilai normatif siswa menunjukkan bahwa rata-rata nilai normatif dari kedua sekolah tersebut tidak berbeda secara signifikan. Hal ini berarti bahwa ratarata nilai normatif siswa Program Keahlian Tata Busana SMK N 4 Yogyakarta dan SMK N 6 Yogyakarta adalah sama.

Tabel 1, Tabel 2, dan Tabel 3, menunjukkan bahwa rerata/mean nilai adaptif sebesar 7,055 (>7,0), dicapai oleh 91 siswa (66,4\%) dari 137 siswa $(<70 \%)$, sehingga dapat dikatakan bahwa siswa SMK Negeri Program Keahlian Tata Busana di Kota Yogyakarta belum berhasil mencapai standar minimal kompetensi nilai adaptif yang telah ditetapkan yaitu $>70 \%$ siswa telah dapat mencapai nilai adaptif dalam kategori baik $(>7,0)$, dan juga dilihat dari sebaran nilai adaptif siswa masih kurang bagus (Nilai Modus= 6,8 < Nilai Median= 7,094 < Nilai Mean=7,055), maka pencapaian nilai adaptif siswa SMK Negeri Program Keahlian Tata Busana di Kota Yogyakarta ini masih perlu diperbaiki dan ditingkatkan lagi. Dengan demikian dapat dikatakan bahwa tingkat keefektifan pembelajaran dengan KBK ditinjau dari pencapaian standar nilai adaptif siswa SMK Negeri Program Keahlian Tata Busana di Kota Yogyakarta masih termasuk dalam kategori cukup dan belum dapat dikategorikan tinggi.

Hasil analisis data statistik deskriptif nilai adaptif menunjukkan bahwa SMKN 4 Yogyakarta mempunyai skor rata-rata 7,1051; sedangkan SMKN 6 Yogyakarta mempunyai skor rata-rata 7,0037; dan hasil Uji-t nilai adaptif siswa menunjukkan bahwa rata-rata nilai adaptif siswa dari kedua 
sekolah tersebut di atas berbeda secara signifikan. Hal ini berarti bahwa rata-rata nilai adaptif siswa Program Keahlian Tata Busana SMKN 4 Yogyakarta dan SMKN 6 Yogyakarta tidak sama, dan dapat dikatakan bahwa rata-rata nilai adaptif siswa Program Keahlian Tata Busana SMKN 4 Yogyakarta lebih tinggi dibandingkan dengan SMKN 6 Yogyakarta.

Tabel 1, Tabel 2, dan Tabel 3, juga menunjukkan bahwa rerata/mean nilai produktif sebesar 7,49 (>7,0), dicapai oleh 127 siswa $(92,7 \%)$ dari 137 siswa $(>70 \%)$, dan yang mencapai rata-rata nilai produktif $\geq 7,5$ baru sebanyak 80 siswa $(58,4 \%)$ dari 137 siswa (<70\%), sehingga dapat dikatakan bahwa siswa SMK Negeri Program Keahlian Tata Busana di Kota Yogyakarta belum berhasil mencapai standar minimal kompetensi nilai produktif yang telah ditetapkan yaitu $>70 \%$ siswa telah dapat mencapai nilai produktif dalam kategori baik $(\geq 7,5)$. Dengan demikian, dapat dikatakan bahwa tingkat keefektifan pembelajaran dengan KBK ditinjau dari pencapaian standar nilai produktif siswa SMK Negeri Program Keahlian Tata Busana di Kota Yogyakarta masih termasuk dalam kategori cukup dan belum dapat dikategorikan tinggi. Walaupun dilihat dari sebaran skor nilai produktif siswa SMK Negeri Program Keahlian Tata Busana di Kota Yogyakarta sudah bagus (Nilai Mean= 7,49 < Nilai Median= 7,532< Nilai Modus $=7,60$ ), karena tingkat keefektifannya belum tinggi maka masih perlu diperbaiki dan ditingkatkan lagi.

Hasil Uji Mann-Whitney (U-test) nilai produktif siswa menunjukkan bahwa rata-rata nilai produktif siswa dari kedua sekolah tersebut di atas berbeda secara signifikan, dan dapat dikatakan bahwa rata-rata nilai produktif siswa Program Keahlian Tata Busana SMKN 4 Yogyakarta $(7,659)$ lebih tinggi dibandingkan dengan SMKN 6 Yogyakartan $(7,3145)$.

Berdasarkan hal tersebut di atas, maka dapat diartikan bahwa untuk mata diklat normatif, siswa SMK Negeri Program Keahlian Tata Busana di Kota Yogyakarta baik SMKN 4 Yogyakarta maupun SMKN 6 Yogyakarta telah dapat mencapai kriteria atau standar yang telah ditentukan, sedangkan untuk mata diklat adaptif dan produktif belum dapat mencapai kriteria yang telah ditetapkan. Namun demikian, mengacu pada kriteria nilai yang telah ditetapkan oleh Depdiknas, maka dapat disebutkan bahwa rata-rata nilai prestasi akademik siswa di kedua sekolah tersebut sudah termasuk dalam 
Pencapaian Standar Kompetensi Siswa SMK Negeri Program Keablian Tata Busana di Kota Yogyakarta dalann Pembelajaran dengan KBK

kategori cukup baik, walaupun nilainya masih cenderung mendekati kategori kriteria batas minimal.

Hasil penelitian tersebut di atas menunjukkan bahwa penguasaan siswa SMK Negeri Program Keahlian Tata Busana di Kota Yogyakarta terhadap kompetensi berupa penguasaan dari aspek kognitif, afektif, dan psikomotor yang merupakan hasil dari program mata diklat normatif, adaptif, dan produktif belum seluruhnya dapat dicapai. Dari ketiga aspek tersebut, baru aspek afektif (mata diklat normatif) saja yang memenuhi kriteria atau standar yang telah ditentukan yaitu $>70 \%$ siswa dapat mencapai nilai rata-rata $>7,0$, sedangkan untuk aspek kognitif (mata diklat adaptif), jumlah siswa yang dapat mencapai kriteria nilai rata-rata $>7,0$ masih $<70 \%$, begitupun dengan aspek psikomotorik (mata diklat produktif), jumlah siswa yang dapat mencapai kriteria nilai rata-rata $\geq 7,5$ juga masih $<70 \%$.

Sehubungan dengan hal di atas, maka tingkat keefektifan kegiatan pembelajaran dengan KBK ditinjau dari pencapaian standar kompetensi mata diklat normatif sudah termasuk dalam kategori tinggi dan memenuhi kriteria efektif sebesar $94,9 \%(>70 \%)$ yaitu jumlah siswa yang telah mencapai nilai >7,0, sehingga dapat dikatakan sudah efektif baik di SMKN 4 Yogyakarta maupun di SMKN 6 Yogyakarta, sedangkan tingkat keefektifan kegiatan pembelajaran dengan KBK ditinjau dari pencapaian standar kompetensi mata diklat adaptif walaupun sudah termasuk tinggi namun baru dapat dicapai sebesar $66,4 \%$ siswa $(<70 \%)$ yang telah mencapai nilai $>7,0$, sehingga dapat dikatakan belum efektif, dan tingkat keefektifan kegiatan pembelajaran dengan KBK ditinjau dari pencapaian standar kompetensi mata diklat adaptif di Program Keahlian Tata Busana SMKN 4 Yogyakarta lebih tinggi dibandingkan dengan SMKN 6 Yogyakarta. Begitupun tingkat keefektifan kegiatan pembelajaran dengan KBK ditinjau dari pencapaian standar kompetensi mata diklat produktif walaupun sudah termasuk tinggi namun baru dapat dicapai oleh sebesar $58,4 \%$ siswa $(<70 \%$ ) yang mencapai nilai $\geq 7,5$, sehingga dapat dikatakan belum efektif, dan tingkat keefektifan kegiatan pembelajaran dengan KBK ditinjau dari pencapaian standar kompetensi mata diklat produktif di 
Jumal Penelitian dan Evaluasi Pendidikan, Nomor 2, Tabun X, 2007

Program Keahlian Tata Busana SMKN 4 Yogyakarta lebih tinggi dibandingkan dengan SMKN 6 Yogyakarta.

Hasil temuan dari penelitian tersebut di atas menunjukkan bahwa baik Program Keahlian Tata Busana SMKN 4 Yogyakarta maupun SMKN 6 Yogyakarta masih membutuhkan perbaikan kualitas pembelajaran kompetensi baik teori maupun praktek, agar sekolah tersebut mampu mengantarkan seluruh siswanya dalam mencapai kompetensi dibidangnya sesuai dengan yang diharapkan.

\section{Kesimpulan}

Berdasarkan hasil analisis data penelitian dan pembahasan secara keseluruhan sebagaimana diuraikan di muka, maka dapat ditarik kesimpulan sebagai berikut.

1. Tingkat keefektifan kegiatan pembelajaran dengan KBK ditinjau dari pencapaian standar kompetensi mata diklat normatif siswa SMK Negeri Program Keahlian Tata Busana di Kota Yogyakarta sudah termasuk dalam kategori tinggi (efektif), dan tidak terdapat perbedaan yang signifikan antara Program Keahlian Tata Busana SMKN 4 Yogyakarta dengan SMKN 6 Yogyakarta.

2. Tingkat keefektifan kegiatan pembelajaran dengan KBK ditinjau dari pencapaian standar kompetensi mata diklat adaptif siswa SMK Negeri Program Keahlian Tata Busana di Kota Yogyakarta belum termasuk dalam kategori tinggi (kurang efektif), dan terdapat perbedaan yang signifikan antara Program Keahlian Tata Busana SMKN 4 Yogyakarta dengan SMKN 6 Yogyakarta, dimana SMKN 4 Yogyakarta lebih tinggi dibandingkan dengan SMKN 6 Yogyakarta.

3. Tingkat keefektifan kegiatan pembelajaran dengan KBK ditinjau dari pencapaian standar kompetensi mata diklat produktif siswa SMK Negeri Program Keahlian Tata Busana di Kota Yogyakarta belum termasuk dalam kategori tinggi (kurang efektif), dan terdapat perbedaan yang signifikan antara Program Keahlian Tata Busana SMKN 4 Yogyakarta dengan SMKN 6 Yogyakarta, dimana SMKN 4 Yogyakarta lebih tinggi dibandingkan dengan SMKN 6 Yogyakarta. 
Pencapaian Standar Kompetensi Sisva SMK Negeri Program Keablian Tata Busana di Kota Yogyakarta dalam Pembelojaran dengan KBK

\section{Daftar Pustaka}

Adib. Gja, aal. (2007). Perjalanan Kurikulum Berbasis Kompetensi (KBK): beberapa catatan pelaksanaan KBK di lingkungan PTAI. Artikel jurnal diambil pada tanggal 31 Januari 2007 dari http://www.ditpertais.net/ swara/warta18-04.asp. Swara Ditpertais: No. 18 Tahun II. 30 Oktober 2004.

Association Educator. (2000). Competency-based education: what, why, and bow? ASAE. American Society of Association Executives, Washington, DC.

Burhanuddin Tola. (2004). Penilaian berbasis kompetensi. Makalah seminar sehari: Konsekuensi sistem evaluasi dalam KBK di auditorium perpustakaan UNILA, tanggal 15 Maret 2004.

Depdiknas. (2003). Pelayanan profesional Kurikulum 2004: Kurikulum Berbasis Kompetensi. Jakarta: Depdiknas.

Depdiknas. (2004). Pedoman supervisi pengajaran. Jakarta: Depdiknas.

Djemari Mardapi. (2004). Implementasi Kurilulum Berbasis Kompetensi. Makalah seminar sehari: Konsekuensi sistem evaluasi dalam KBK di auditorium perpustakaan UNILA, tanggal 15 Maret 2004.

Gonezi, A. (1992). Developing a competent workforce. NCVER. Adealide. Aus.

Harris, R., \& Guthrie, H., \& Hobart, B., \& Lundberg, D. (1995). Competency-Based Education and Training. South Yarra, Australia: Macmillan Education.

Spencer, L.M., \& Spencer, S.M. (1993). Competence work: models for superior performance. John Wiley \& Sons, Inc. New York.

Zamroni dan Dyah W. (2004). Refleksi pelaksanaan KBK pada tingkeat Sekolab Menengah Atas. Makalah disajikan dalam seminar nasional dengan tema refleksi pelaksanaan Kurikulum Berbasis Kompetensi dalam rangka Dies Natalis XI pada tanggal 17 Mei 2004 di UNY. 


\section{Biodata Penulis}

Widihastuti. Lahir di Sleman, 15 Nopember 1972. Pendidikan S1, Prodi Pendidikan Teknologi dan Kejuruan, IKIP Yogyakarta tahun 1998. Pendidikan S2, Prodi Penelitian dan Evaluasi Pendidikan, Universitas Negeri Yogyakarta tahun 2007. Pekerjaan, Dosen Mata Kuliah Analisa Tekstil, Teknologi Kimia Tekstil, dan Statistika, Jurusan Pendidikan Teknik Boga dan Busana Fakultas Teknik Universitas Negeri Yogyakarta. Karya ilmiah antara lain: Efektivitas Pelaksanaan KBK pada SMK Negeri Program Keablian Tata Busana di Kota Yogyakarta Ditinjau dari Pencapaian Standar Kompetensi Siswa, Tesis PPS UNY (2007). 